\title{
DENDROBENTHAMIDIA CAPITATA (WALL.) HUTCH. FRUIT (BHOMORA): AN OPULENT SOURCE OF POLYPHENOLS WITH ANTIOXIDANT, ANTI-ELASTASE, ANTI-COLLAGENASE, AND ANTI-TYROSINASE ACTIVITIES FROM INDIAN HIMALAYAN REGION
}

\author{
Himani Singh, Madhuri Kaushish Lily and Koushalya Dangwal*
}

Biotechnology Laboratory, Department of Science, Modern Institute of Technology, Dhalwala, Rishikesh, Uttarakhand, India

Corresponding Author E-mail: kdangwal1@yahoo.co.in

Received: 20.06.2019; Revised: 16.07.2019; Accepted: 17.10.2019

OSociety for Himalayan Action Research and Development

\begin{abstract}
Dendrobenthamidia capitata (Wall.) Hutch. fruit (Bhamora) is a popular yet underexplored wild edible fruit of Uttarakhand state of Indian Himalayan region. Therefore, the present study was aimed to analyze D. capitata fruit for its phenolic contents, antioxidant, anti-elastase, anti-collagenase, and anti-tyrosinase activities using in- vitro assays. Phenolics and flavonoids were extracted using $80 \%$ aqueous acetone and acid acetone as solvents. Our analysis revealed high values of total phenolic contents of $4.38 \pm 0.08 \mathrm{mg}$ gallic acid equivalents (GAE). $\mathrm{g}^{-1}$ fruit weight and total flavonoid contents of $7.47 \pm 0.66 \mathrm{mg}$ catechin equivalents $(\mathrm{CE}) . \mathrm{g}^{-1}$ fruit weight in the acid acetone fruit extracts of $D$. capitata. D. capitata fruit extracts demonstrated remarkable antioxidant activities (ABTS+, 1,1diphenyl-2-picrylhydrazyl, superoxide anion, linoleate peroxyl radicals scavenging, and ferric reducing activities) and notable anti-elastase, anti-collagenase, and anti-tyrosinase activities. High resolution liquid chromatographymass spectroscopy analysis revealed presence of six phenolic compounds, namely, dihydrorobinetin, dhydromyricetin, retusin dimethyl ether, rotenone, bergenin (C-glycoside of 4-O-methyl gallic acid) and peucenin in fruit extracts. This study recommends utilization of D.capitata fruit as functional food with prospective pharmaceutical, nutraceutical, and cosmeceutical properties.
\end{abstract}

Keywords: Wild edible fruits, D. capitata, Antioxidant, Anti-elastase, Anti-collagenase, Anti-tyrosinase

\section{Introduction}

Increased consumption of vegetables and fruits has been acknowledged to be associated with lower risk of a number of chronic diseases, such as coronary heart diseases, cancers, immune dysfunction and diabetes owing to their unique combination of minerals, vitamins and polyphenols (Pandey and Rizvi, 2009). Recently, fruits have attracted tremendous attention among food scientists, nutritionists and consumers owing to their multiple health promoting properties including antioxidant, antimicrobial, anticancerous, antidiabetic, anti-inflammatory, anti-skin aging and anti-skin darkening activities associated with elevated polyphenol contents and delicious taste respectively (Wang et al., 1996; Sun et al., 2002; Mathur et al., 2011; Mueller et al., 2010; Dai and Mumper, 2010; Li et al., 2014; Mukherjee et al., 2011; Hu 2011; Chang 2009). Furthermore to cultivated fruits, wild edible fruits have also gained global concern due to their higher polyphenol contents and outstanding antioxidant activities (Meda et al., 2008; Chalise et al., 2010; Fu et al., 2010; Murillo et al. 2012; Siqueira et al., 2013). In continuation to the worldwide research, wild edible fruits of Indian Himalayan region (IHR) have also emerged as potential source of nutraceuticals including polyphenols with antioxidant, anticancer, anti- 
inflammatory, anti-skin aging and skin lightening activities (Saini et al., 2012; Saini et al., 2013; Seal, 2011; Seal et al., 2013; Singh et al., 2014; Nayak and Chand, 2015; Singh 2015; Singh et al., 2017; Baral and Chand, 2017; Bhatt et al., 2017). Dendrobenthamidia capitata (Wall.) Hutch. is one of the underexplored fruits of IHR, locally known as Bhamora (commonly recognized as Himalayan strawberry) belongs to family Cornaceae is a subdeciduous tree commonly found in mixed OakRhododendron forests of montane zones at 1500$2500 \mathrm{~m}$ altitude in the IHR (Gaur, 1999). Ripe fruits are pinkish-red, in globose heads, 2.5-3.0 $\mathrm{cm}$ across, succulent and each drupe one seeded. Recent preliminary studies on $D$. capitata fruits indicated presence of high nutritional composition along with moderate levels of polyphenols and associated bioactivities including antioxidant antiinflammatory, anti-skin aging and skin-lightening activities (Singh et al., 2015; Rana et al., 2018). Present study was focused on systematic evaluation of total phenolic and flavonoid contents of D. capitata fruit extracts. Study was also aimed to determine the antioxidant, anti-skin aging and skin lightening activities of the fruit extracts using in-vitro assays.

\section{Materials and Methods}

General chemicals used in the study were more than $99 \%$ pure and of analytical grade procured from HiMedia Pvt. Ltd. (Mumbai, India). 2,2'azinobis-3-ethylbenzothiazoline-6-sulphonic acid (ABTS) was obtained from Calbiochem, Merck Pvt. Ltd. (Darmstadt, Germany). 1,1-diphenyl-2picrylhydrazyl (DPPH), nicotinamide adenine dinucleotide (NADH), phenyl methosulfate (PMS), nitro blue tetrazolium (NBT), linoleic acid, $\beta$-carotene, catechin, ferrozine, catechin, kojic acid, epigallocatechingallate (EGCG), Nsuccinyl-ala-ala-ala-p-nitroanilide (AAAPVN), N[3-(2-furyl)acryloyl]-leu-gly-pro-ala (FALGPA), 3-4-dihydroxy-L-phenylalanine (L-DOPA) and Clostridium histolyticum collagenase (EC 3.4.24.3), porcine pancreatic elastase (EC 3.4.21.36), and mushroom tyrosinase (EC 1.14.18.1) were purchased from Sigma-Aldrich (St Louis,MO, USA).

\section{Collection, identification, and authentication of fruit}

Fruit samples (along with small twig containing leaves) (half ripened as fully ripened fruits were unavailable) were harvested from various locations of Ramgarhtalla District Nainital in Uttarakhand state of India during the month of November. Fresh fruits were cleaned with running tap water and kept at $-20^{\circ} \mathrm{C}$ until use within 1 month. The herbarium of fruit samples was authenticated by Botany division of Botanical Survey of India (BSI), Dehradun, Uttarakhand, India.

\section{Evaluation of total phenolic contents (TPCs) and total flavonoid contents (TFCs)}

Fruit extracts were prepared with $80 \%$ aqueous acetone and acid acetone as solvents (Saini et al., 2012).The TPCs were determined by FolinCiocalteau method (Singleton et al., 1999). Briefly, fruit extracts $(1 \mathrm{ml})$ was incubated with Folin-Ciocalteau reagent $(0.2 \mathrm{~N}, 2.5 \mathrm{ml})$ at room temperature (RT) for $5 \mathrm{~min}$. Thereafter, sodium carbonate solution (75 g. . $^{-1}$ in water, $2 \mathrm{ml}$ ) was added and further incubated for $2 \mathrm{~h}$. Absorbance was measured using ultraviolet-visible (UV-Vis) spectrophotometer (Systronics, India, Model No. 119) at $760 \mathrm{~nm}$ against water control. A standard calibration curve was plotted using gallic acid $(0.2$ $\left.\mathrm{mg} . \mathrm{ml}^{-1}\right)$. The TPCs were expressed as $\mathrm{mg}$ gallic acid equivalent (GAE). $\mathrm{g}^{-1}$ fruit weight (FW).TFCs of fruit extracts were determined according to Chang et al. (2002). For that, diluted extracts $(0.6$ $\mathrm{ml})$ were incubated with sodium nitrite solution $(5 \%, 0.3 \mathrm{ml})$ at $\mathrm{RT}$ for $5 \mathrm{~min}$. Afterwards, aluminium trichloride solution $(10 \%, 0.6 \mathrm{ml})$ was added and incubated further for $5 \mathrm{~min}$. Absorbance was measured at $510 \mathrm{~nm}$ against water blank and TFC was expressed as $\mathrm{mg}$ catechin equivalents (CE). $\mathrm{g}^{-1} \mathrm{FW}$ using catechin $\left(0.5 \mathrm{mg} . \mathrm{ml}^{-1}\right)$ as standard.

\section{Antioxidant activity}

http://jmr.sharadpauri.org 
Antioxidant activities of fruit extracts were evaluated as free radical scavenging activities such as DPPH radical scavenging activity (DPPHRSA), ABTS+ radical scavenging activity (ABTSRSA), linoleate hydroperoxide radical scavenging activity (LPRSA), superoxide radicals scavenging activity (SORSA), ferric reducing activity (FRA) using the protocols mentioned by Saini et al. (2014).

\section{Anti-elastase and anti-collagenase activity}

Anti-elastase and anti-collagenase activities were determined according to Kim et al. (2004) for anti-collagenase assay; fruit extracts were preincubated with the collagenase enzyme (stock 0.8 $\mathrm{U}_{\mathrm{ml}}{ }^{-1}$ ) for $15 \mathrm{~min}$ before adding substrate to start the reaction. The final reaction mixture $(150 \mu \mathrm{l})$ contained 50mM Tricine buffer, $0.8 \mathrm{mM}$ synthetic substrate FALGPA, 0.1 unit collagenase and various dilutions of fruit extracts. Absorbance at $335 \mathrm{~nm}$ was measured immediately after adding substrate and then continuously for $20 \mathrm{~min}$ using microplate reader (Fluostar Optima, BMG Labtech, Germany). Anti-collagenase activity of fruit extracts was determined as mg EGCG equivalents. $\mathrm{g}^{-1} \mathrm{FW}$. EGCG $(250 \mu \mathrm{M})$ was used as standard inhibitor. Anti-elastase assay involved incubation of fruit extracts with the porcine pancreatic elastase (stock solution $3.33 \mathrm{mg} \cdot \mathrm{ml}^{-1}$ in sterile water) for $15 \mathrm{~min}$ before adding the substrate. The final reaction mixture $(250 \mu \mathrm{l})$ contained $0.2 \mathrm{mM}$ Tris- $\mathrm{HCl}$ buffer ( $\mathrm{pH}$ 8.0), substrate $0.8 \mathrm{mMAAAPVN}, 1 \mu \mathrm{g} \cdot \mathrm{ml}^{-1}$ elastase and $25 \mu \mathrm{l}$ fruit extracts. Absorbance values between 381 and $402 \mathrm{~nm}$ (following pre-screen scans) were measured continuously for $20 \mathrm{~min}$ after adding substrate. EGCG $(250 \mu \mathrm{M})$ was used as a standard and anti-elastase activity of the fruit extracts was represented as mg EGCG equivalents. $\mathrm{g}^{-1} \mathrm{FW}$.

\section{Anti-tyrosinase activity}

Anti-tyrosinase activity was evaluated with respect to fruit extracts ability to inhibit mushroom tyrosinase enzyme (Masamota et al., 1980). Reaction mixture included phosphate buffers $(0.1 \mathrm{M}, 20 \mu \mathrm{l}, \mathrm{pH} 6.8)$, L-DOPA $(0.85 \mathrm{mM}$, $20 \mu \mathrm{l})$ as the substrate, and $20 \mu \mathrm{l}$ diluted fruit extracts was incubated at $25^{\circ} \mathrm{C}$ for $10 \mathrm{~min}$. Afterwards, mushroom tyrosinase (1000 U.ml ${ }^{-1}$, $20 \mu \mathrm{l})$ was added to initiate the reaction and incubated for $25 \mathrm{~min}$. The absorbance was measured at $492 \mathrm{~nm}$. Kojic acid $\left(0.5 \mathrm{mg} \cdot \mathrm{ml}^{-1}\right)$ was used as positive control and anti-tyrosinase activity was measured as milligrams of kojic acid equivalents (KAE). $\mathrm{g}^{-1} \mathrm{FW}$.

\section{HR-LC-MS}

HR-LC-MS analysis of D. capitata fruit extracts was performed at Sophisticated Analytical InstrumentFacility (SAIF), Indian Institute of Technology, Mumbai, Maharashtra, India on commercial basis (Singh et al., 2016). A small quantity of dried sample was dissolved with $80 \%$ acetone, and filtered through a glass syringe using $0.2 \mu \mathrm{m}$ filter and then analyzed in UHPLC (1290 Infinity Binary pump, Agilent Technologies) coupled with 6550 i-Funnel QTOF mass spectrometer (the mobile phase was a gradient of $0.1 \%$ formic acid in water and $0.1 \%$ formic acid in acetonitrile $(\mathrm{ACN})$ at a flow rate of $0.3 \mathrm{ml} \cdot \mathrm{min}^{-1}$ for 30min. The column used was Zorbax SBC18 Rapid Resolution HD, $2.1 \times 100 \mathrm{~mm}, 1.8 \mu \mathrm{m}$ (Agilent Technologies, USA). The nitrogen gas flow was $13 \mathrm{ml} \cdot \mathrm{min}^{-1}$ at $25^{\circ} \mathrm{C}$, and the sheath gas flow was $11 \mathrm{ml} \cdot \mathrm{min}^{-1}$ at $30^{\circ} \mathrm{C}$ with a nebulizer pressure at 35 psi. The capillary voltage was 3500 $\mathrm{V}$ with a nozzle voltage of $1000 \mathrm{~V}$. Fragmentation energy was kept at $175 \mathrm{~V}$. The analysis was done in both +ESI and -ESI mode, the data was acquired in Agilent Masshunter Data Acquisition software (Version B.05.00) and the data were analyzed in Agilent Masshunter Qualitative Software (Version B.06.00).

\section{Statistical analysis}

To rule out any inconsistencies, three independent extractions were performed and each extract was analyzed at least three times for each parameter. The results were expressed as mean of three independent experiments $(n=3)$ with calculation of standard error (SE). The statistical analysis of the data was performed using MS Excel and Prism 3 pad software (Microsoft, Redmond, WA, USA).

\section{Results}




\section{TPC and TFC}

The TPC was evaluated using gallic acid as standard $\left(\mathrm{R}^{2}=0.999\right)$. The result showed significantly higher $(p<0.001)$ TPC in acid acetone $\left(3.57 \pm 0.12 \mathrm{mg}\right.$ GAE. $\left.{ }^{-1} \mathrm{FW}\right)$ than in acetone fruit extracts $\left(4.38 \pm 0.08 \mathrm{mg}\right.$ GAE. $\mathrm{g}^{-1}$ FW). The TFC was determined using catechin as standard $\left(\mathrm{R}^{2}=09996\right)$. The acid acetone fruit extract showed significantly higher TFC $\left(7.47 \pm 0.66 \mathrm{mg} \mathrm{CE} . \mathrm{g}^{-1} \mathrm{FW}\right)$ than that of acetone extracts $(3.38 \pm 0.2 \mathrm{mg} \mathrm{CE} / \mathrm{g} \mathrm{FW})$.

Table 1 TPC and TFC of D. capitata fruit extracts

\begin{tabular}{|l|l|l|}
\hline Extracts & $\begin{array}{l}\text { TPC } \\
\text { mg GAE. } \mathbf{g}^{\mathbf{1}} \mathbf{~ F W}\end{array}$ & $\begin{array}{l}\text { TFC } \\
\text { mg CE. } \mathbf{g}^{-\mathbf{1}} \mathbf{F W}\end{array}$ \\
\hline $\begin{array}{l}80 \% \text { acetone } \\
\text { extracts }\end{array}$ & $3.67 \pm 0.12$ & $3.78 \pm 0.2$ \\
\hline $\begin{array}{l}80 \% \text { acid } \\
\text { acetone } \\
\text { extracts }\end{array}$ & $4.38 \pm 0.08$ & $7.47 \pm 0.66$ \\
\hline
\end{tabular}

Each value was expressed as mean $\pm \operatorname{SE~}(n=3)$.

\section{Antioxidant activity}

The antioxidant activities of $D$. capitata fruit extracts were determined using various parameters such as free radical scavenging activities against four different types of free radicals (ABTS ${ }^{+}$, $\mathrm{DPPH}$, linoleate peroxide, ferric and superoxide) and ferric reducing activities (Table 2). The ABTS assay measures the ability of fruit extracts to scavenge the cationic radical $\mathrm{ABTS}^{+}$produced by the oxidation of ABTS. The blue green colored $\mathrm{ABTS}^{+}$cation radicals are reduced to its nonradical, colorless ABTS form by the fruit antioxidants. We observed high levels of ABTS scavenging activity in both the extracts. It was slightly higher in acid acetone extract $(6.83 \pm 0.23$ mg BHAE. $\left.\mathrm{g}^{-1} \mathrm{FW}\right)$ than that in acetone extracts (Table 2). This was further confirmed by lower concentration of acid acetone extracts required to inhibit $50 \%$ of ABTS radical inhibition (IC50) (Table 3). The DPPH scavenging activity of extracts is based on the ability of fruit phenols to neutralize the stable and neutral free radical DPPH (Gulcin et al., 2010). The DPPH free radical

Table 2 Free radical scavenging activities and ferric reducing activities of $D$. capitata fruit extracts scavenging activity was found to be marginally higher in acid acetone extracts $(9.53 \pm 0.11 \mathrm{mg}$ CE.g ${ }^{-1} \mathrm{FW}$ ) as compared to that in acetone extracts. This higher recovery of DPPH scavenging phenols in acid acetone fruit extracts was further established by its lower IC50 values which were even much lower than that was shown by ascorbic acid standard (Table 3). Linoleate hydroperoxide radical scavenging activity (LPRSA) of fruit extracts were determined through $\beta$-carotene bleaching test which involved production of linoleate hydroperoxide as free radicals at $50{ }^{\circ} \mathrm{C}$. These free radicals interact with $\beta$-carotene, leading to its bleaching. Thus, the $\beta$ carotene bleaching rate is inversely proportional to the antioxidant activity of extracts that neutralize free radical formed in the system. Linoleate peroxide scavenging activities was faintly higher in acid acetone extracts than that in acetone fruit extracts which was also evident by its lower IC50 values of acetone fruit extracts (Table 3). Superoxide $\left(\mathrm{O}^{2-}\right)$ is the reactive oxygen radical produced by one-electron reduction of molecular oxygen in metabolic processes and is the major source of other radicals (Liu et al., 1997). Therefore, it was very important to examine the superoxide anion radical scavenging ability of $D$. capitata fruit extracts. This assay determines the ability of fruit extracts to neutralize the superoxide anion radicals generated in the PMS/NADH system which subsequently leads to a decrease in the reduction of nitroblue tetrazolium to a chromogenic product. The higher superoxide scavenging activity was seen in the acid acetone

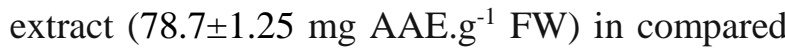
to acetone fruit extracts (Table 2). The IC50 values of the acid acetone fruit was also lower than acetone fruit extracts (Table 3). The ferric reducing assay measures the ability of phenolics to reduce $\mathrm{Fe}^{3+}$ to $\mathrm{Fe}^{2+}$. The ferric reducing activity of acid acetone fruit extracts was $15.84 \pm 1.25 \mathrm{mg}$ AAE. $\mathrm{g}^{-1} \mathrm{FW}$ higher than the acetone fruit extracts (Table 2). 


\begin{tabular}{|c|c|c|c|c|c|}
\hline \multirow[t]{2}{*}{ Extracts } & $\mathbf{A B T S}^{\cdot+} \mathbf{R S A}$ & DPPHRSA & LPRSA & \multirow{2}{*}{$\begin{array}{l}\text { SORSA } \\
\mathrm{mg} \mathrm{CE} \cdot \mathrm{g}^{-1} \mathrm{FW}\end{array}$} & \multirow{2}{*}{$\begin{array}{ll}\text { FRA } & \\
\text { mg } & \text { AAE. }{ }^{-1} \\
\text { FW } & \\
\end{array}$} \\
\hline & $\begin{array}{l}\text { mg } \quad \text { BHAE. } g^{-1} \\
\text { FW }\end{array}$ & $\begin{array}{l}\text { mg } \\
\text { FW }\end{array}$ & $\begin{array}{l}\text { mg BHAE.g- } \\
\text { FW }\end{array}$ & & \\
\hline & $6.46 \pm 0.08$ & $9.53 \pm 0.11$ & $27.74 \pm 4.54$ & $71.52 \pm 0.05$ & $12.63 \pm 0.42$ \\
\hline 14 a & $6.83 \pm 0.23$ & $1.04 \pm 0.16$ & $28.29 \pm 3.49$ & $78.7 \pm 1.25$ & $15.84 \pm 1.25$ \\
\hline
\end{tabular}

Each value was expressed as mean \pm SE $(n=3)$.ABTS ${ }^{+}{ }^{+R S A}:$ ABTS $^{+}$radical scavenging activity; DPPHRSA: DPPH scavenging activity; LPRSA: Linoleate peroxide radical scavenging activity; SORSA: Superoxide radical scavenging activity; FRA: Ferric reducing activity

Table 3 IC50 values of the free radical scavenging activities

\begin{tabular}{|l|l|l|l|l|}
\hline \multirow{2}{*}{ Extracts } & \multicolumn{4}{l}{ IC50 of Free radical scavenging activities } \\
\cline { 2 - 5 } & ABTS ${ }^{+} \mathrm{RSA}$ & DPPHRSA & LPRSA & SORSA \\
\hline Acetone $\left(\mathrm{mg} \cdot \mathrm{ml}^{-1}\right)$ & 1.482 & 1.008 & 1.830 & 1.641 \\
\hline Acid acetone $\left(\mathrm{mg} \cdot \mathrm{ml}^{-1}\right)$ & 1.376 & 0.936 & 1.787 & 1.237 \\
\hline BHAE $\left(\mu \mathrm{g} \cdot \mathrm{ml}^{-1}\right)$ & 8.71 & & 6.807 & \\
\hline AAE $\left(\mathrm{mg} \cdot \mathrm{ml}^{-1}\right)$ & & 4.258 & & \\
\hline CE $\left(\mu \mathrm{g} \cdot \mathrm{ml}^{-1}\right)$ & & & & 12.815 \\
\hline
\end{tabular}

$\mathrm{IC}_{50}$ : concentration of extracts required to inhibit $50 \%$ free radicals.

\section{Anti-elastase and anti-collagenase activities}

Elastase and collagenase are the enzymes located in extracellular matrix. They are responsible for breaking elastin and collagen fibers, the main components of extracellular matrix and thus leading to loosening of skin resulting in skin aging. Anti-elastase and anti-collagenase activities of the fruit extracts were determined by using EGCG as standard inhibitor $\left(\mathrm{R}^{2}=0.984\right.$ and $\mathrm{R}^{2}=$ 0.971 , respectively). The observations showed overall low anti-elastase activity in both the extracts of D. capitata fruit though it was significantly higher in acid acetone extracts (5.7 $\pm 1.26 \mathrm{mg}$ EGCGE. $\left.{ }^{-1} \mathrm{FW}\right)$. In contrary to low anti-elastase activity, both the $D$. capitata fruit extracts showed admirable anti-collagenase activities. The activity was better in acid acetone fruit extracts $\left(25.68 \pm 1.77 \mathrm{mg}\right.$ EGCGE. $\left.{ }^{-1} \mathrm{FW}\right)$ than in acetone extracts.

Table4: Anti-elastase, anti collagenase and anti-tyrosinase activities of D.capitata fruit extracts

\begin{tabular}{|l|l|l|l|}
\hline Extracts & $\begin{array}{l}\text { Anti-elastase assay } \\
\text { mg EGCGE.g }\end{array}$ & $\begin{array}{l}\text { Anti-collagenase assay } \\
\text { mg EGCGE.g }\end{array}$ & $\begin{array}{l}\text { Anti-Tyrosinase assay } \\
\text { mg KJE.g }^{-1} \mathbf{~ F W ~}\end{array}$ \\
\hline Acetone & $1.09 \pm 0.033$ & $21.89 \pm 0.36$ & $72.46 \pm 2.96$ \\
\hline Acid acetone & $5.7 \pm 0.17$ & $25.68 \pm 1.77$ & $65.56 \pm 1.37$ \\
\hline
\end{tabular}

Each value was expressed as mean $\pm \operatorname{SE}(n=3)$.

\section{Anti-tyrosinase activity}

Tyrosinase enzyme is one of the key enzymes involved in the melanin biosynthetic pathway responsible for darkening of skin color. Therefore, any tyrosinase inhibiting activity is considered as skin lightening activity. Anti-tyrosinase activity of the $D$. capitata fruit extracts was determined using kojic acid as standard inhibitor of tyrosinase enzyme $\left(R^{2}=0.969\right)$. The observation showed noteworthy anti-tyrosinase activity in both the 
extracts (Table 5). It was higher in acetone fruit extract $\left(72.46 \pm 2.96 \mathrm{mg} \mathrm{KAE} . \mathbf{g}^{-1} \mathrm{FW}\right)$.

\section{Polyphenolic Composition}

Composition of phenolic compounds in aqueous acetone fruit extracts of $B$. capitata was determined qualitatively by HR-LC-MS analysis. The identification of compounds was performed by comparing their mass spectra and fragmentation pattern with polyphenol database (supplied by Agilent Technologies) using Agilent Masshunter Qualitative Software (Version B.06.00). The analysis revealed presence of four flavonoid compounds (dihydrorobinetin, dihydromyricetin, retusin dimethyl ether, rotenone) while two phenolic acid derivatives (bergenin or C-glycoside of 4-O-methyl gallic acid and peucenin) in D. capitata fruit extracts (Table 6; Fig. 1)

Table 5. Polyphenolic composition of the acetone fruit extracts of D. capitata.

\begin{tabular}{|l|l|l|l|l|l|}
\hline S.No. & Compounds & $\begin{array}{l}\text { Retention } \\
\text { time (min.) }\end{array}$ & MS (m.z $\left.\mathbf{z}^{\mathbf{- 1}}\right)$ & Mass & Formula \\
\hline 1 & Dihydrorobinetin & 9.66 & 287.0526 & 304.0559 & $\mathrm{C}_{15} \mathrm{H}_{12} \mathrm{O}_{7}$ \\
\hline 2 & Dihydromyricetin & 12.008 & 303.0469 & 320.0503 & $\mathrm{C}_{15} \mathrm{H}_{12} \mathrm{O}_{8}$ \\
\hline 3 & $\begin{array}{l}\text { Bergenin (C-Gycoside of } \\
\text { 4-O-methyl gallic acid) }\end{array}$ & 0.898 & 351.0651 & 328.0758 & $\mathrm{C}_{14} \mathrm{H}_{16} \mathrm{O}_{9}$ \\
\hline 4 & Retusin dimethyl ether & 0.916 & 335.0898 & 312.0994 & $\mathrm{C}_{18} \mathrm{H}_{16} \mathrm{O}_{5}$ \\
\hline 5 & Peucenin & 20.864 & 243.0996 & 260.1029 & $\mathrm{C}_{15} \mathrm{H}_{16} \mathrm{O}_{4}$ \\
\hline 6 & Rotenone & 5.186 & 415.0957 & 394.1429 & $\mathrm{C}_{23} \mathrm{H}_{22} \mathrm{O}_{6}$ \\
\hline
\end{tabular}
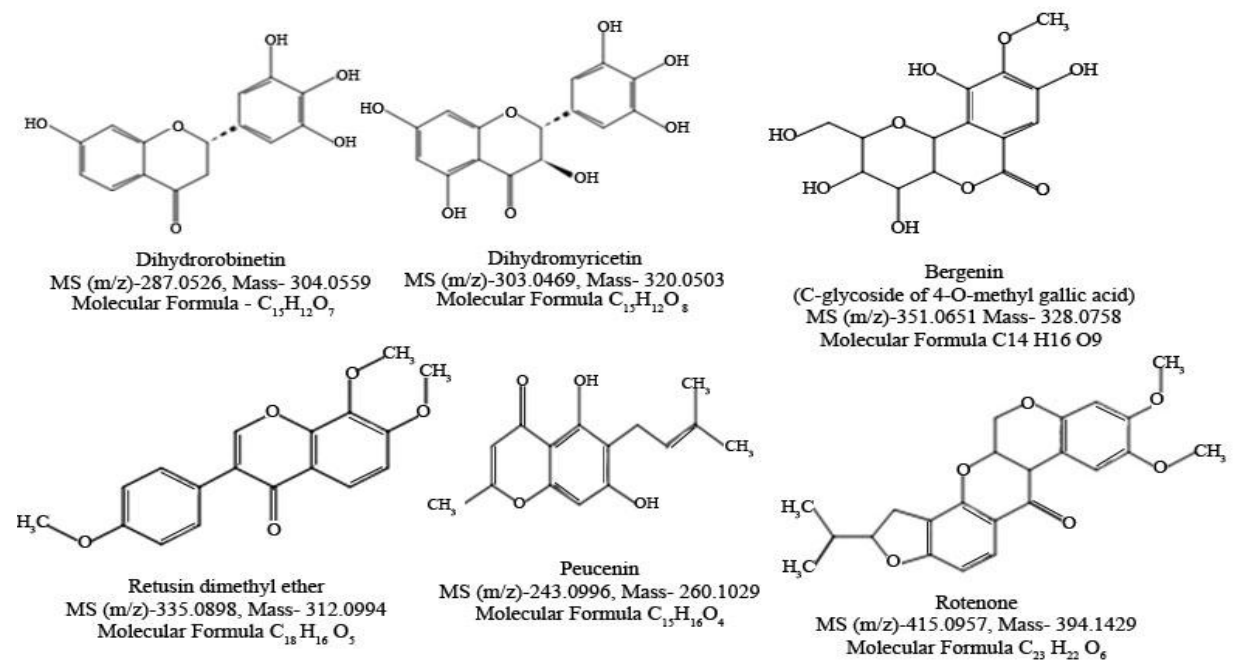

Fig. 1: Polyphenolic composition by HR-LS-MS analysis in D. capitata Discussion

Present study is the first report demonstrating $D$. capitata fruit as the abundant source of phenolics and flavonoids endowed with excellent antioxidant, strong anti-aging and skin lightening activities. Previous studies in our laboratory and others demonstrated $80 \%$ acetone and acid acetone as the best solvent for maximum recovery of polyphenols and associated bioactivities (Meda et al., 2008; Seal, 2011; Saini et al., 2012; Saini et al., 2013; Saini et al., 2014). Therefore, present study used $80 \%$ aqueous acetone and acid acetone as solvent for the extraction of phenolics and 
flavonoids from $D$. capitata fruits. The present study demonstrated significantly higher level of TPC and TFC flavonoid contents in acid acetone extracts of D. capitata fruit Himalayan. This is due to the fact that acidic conditions leads to enhanced hydrolysis of bound polyphenol glucosides (phenolic acid and flavonoid glycosides) aiding into elevated recoveries of the same (Rice-Evans, 2002; Meda et al., 2008; Gorinstein et al., 2011). Our result of high phenolics and flavonoids in D. capitata fruit is supported by the previous study by Singh et al. (2015) who reported $356.66 \pm 12.00 \mathrm{mg}$ GAE.100 $\mathrm{g}^{-1}$ FW and 337.75 CE. $100 \mathrm{~g}^{-1}$ FW TPC and TFC respectively in acetone fruit extracts. Our study evidently demonstrated presence of significant free radical scavenging activities against a diverse range of free radicals (DPPH neutral, ABTS cationic, superoxide anionic, and linoleate hydroperoxide free radicals) and noteworthy ferric reducing activity in acid acetone extracts. The phenolics and flavonoid contents of various extracts were very well correlated with their free radical scavenging and ferric reducing activities suggesting their equal contribution in the antioxidant activities. Our observations on antioxidant activities of $D$. capitata fruits are in consonance with the previous studies by Singh et al. (2015) in the same fruit and other in wild edible fruit (Meda et al., 2008) which showed high polyphenol contents and their high antioxidant capacities. D. capitata fruit extracts also showed excellent anti-collagenase and anti-tyrosinase activities which was much better than that demonstrated bSingh et al. (2016) in the acetone fruit extracts of $D$. capitata. Our findings are also supported by the presence of dihydromyricetinin fruit extracts which was earlier shown to inhibit MMP-9 protease. In addition, till date, many phenolic and flavonoid compounds have been shown to possess anti-skin aging and skinlightening activities by inhibiting elastase, collagenase and tyrosinase enzymes respectively in in vitro assays (Mukherjee et al., 2011; Orhan et al., 2014; Jennifer et al., 2012; Binic et al., 2013; Zhang et al., 2014; Li et al., 2014; Kim et al., 2015).

\section{Conclusion}

The ability of phytochemicals of Himalyan strawberry i.e., D. capitata acetone and acid acetone fruit extract to scavenge a variety of free radicals, and to selectively inhibit collagenase and tyrosinase enzymes are highly appreciable; this implies that the $D$. capitata fruit or fruit extract may be consumed to maintain the antioxidant levels of the body which may in turn prevent the free radicals mediated pathological diseases and slow down the premature skin aging and sun-light induced darkening of skin. Alternatively, fruit extracts could be employed to develop the newer, safer and effective skin cosmetic creams that fight premature skin aging and tanning.

\section{Acknowledgement}

We are highly obliged to Dr. Partha Roy, Department of Biotechnology, Indian Institute of Technology, Roorkee, UK, India, for providing instrumentation facility for anti-elastase, anticollagenase, and anti-tyrosinase activity analysis. Authors also acknowledge the SAIF, Indian Institute of Technology, Mumbai, Maharashtra, India for the timely completion of HR-LC-MS analysis of fruit extracts samples.

\section{Funding}

The authors are grateful for financial support of this study which was provided in part by the Uttarakhand State Biotechnology Programme, Uttarakhand, India (USBD 06/Guard7/K.Dangwal/R\&D Project/Rishikesh/2012) and Modern Institute of Technology, Rishikesh, Uttarakhand, India.

\section{References}

Baral, S and Chand, BU (2017) Assessment of free radical scavenging activity in some 
wild edible fruits of Odisha, India. $J$. Basic. Appl. Sci. Res. 7(5): 1-11

Bhatt, ID, Rawat, S, Badhani, A and Rawal, RS (2017) Nutraceutical potential of selected wild edible fruits of the Indian Himalayan region, Food Chem. 215: 84-91.

Binic, I, Lazarevic, V, Ljubenovic, M, Mojsa, J and Sokolovic, D (2013) Skin ageing: Natural weapons and strategies. eCAM, Article ID 827248, 10 pages.

Chalise, JP, Acharya, K, Gurung, N, Bhusal, RP, Gurung, R, Basnet, NS and Basnet, P (2010) Antioxidant activity and polyphenol content in edible wild fruits from Nepal. Int. J. Food Sci. Nutr. 61: 425-432.

Chang Te-Sheng (2009) An updated review of tyrosinase inhibitors. Int. J. Mol. Sci. 10: 2440-2475.

Chang, CC, Yang, MH, Wen, HM and Chern, JC (2002) Estimation of total flavonoid content in propolis by two complementary colorimetric methods. J. Food Drug Anal. 10: 178-182.

Dai, J and Mumper, RJ (2010) Plant phenolics: extraction, analysis and their antioxidant and anticancer properties. Molecules 15: 73137352.

$\mathrm{Fu}, \mathrm{L}, \mathrm{Xu}, \mathrm{BT}, \mathrm{Xu}, \mathrm{XR}$, Qin, XS, Gan, RY and Li, HB (2010) Antioxidant capacities and total phenolic contents of 56 wild fruits from South China. Molecules 15: 8602-8617.

Gaur, RD (1999) Flora of the District Garhwal, North West Himalaya: With ethnobotanical notes, (pp. 811), TransMedia, Uttarakhand, India.

$\mathrm{Hu}$, ML (2011) Dietary polyphenols as antioxidants and anticancer agents: more questions than answers. Chang Gung Med.J. 34: 449-460.

Jennifer, RC, Stephie, CM, Abhishri, SB and Shalini, BU (2012) A review on skin whitening properties of plant extract. Int. J. Pharma BioSci. 3: 332-347.

Kim, YC, Choi, SY and Park, EY (2015) Antimelanogenic effects of black, green, and white tea extracts on immortalized melanocytes. $J$. Vet. Sci. 16: 135-143.
Kim, YJ, Uyama, H and Kobayashi, S (2004) Inhibition effects of (+)-Catechin aldehyde polycondensates on proteinases causing proteolytic degradation of extracellular matrix. Biochem. Biophys. Res. Commun. 320: 256-261.

Li, HR, Habasi, M, Xie, LZ and Aisa, HA (2014) Effect of chlorogenic acid on melanogenesis of B16 melanoma cells. Molecules 19: 1294012948.

Li, HR, Habasi, M, Xie, LZ and Aisa, HA (2014) Effect of Chlorogenic Acid on Melanogenesis of B16 Melanoma Cells. Molecules 19: 12940-12948.

Masamoto, Y, Iida, S and Kubo, M (1980) Inhibitory effect of Chinese crude drugs on tyrosinase. Planta Med. 40: 361-365.

Mathur, A, Verma, SK, Purohit, R and Singh, S (2011) Evaluation of in vitro antimicrobial and antioxidant activities of peel and pulp of some citrus fruits. J. Biotechnol. Biother. 1: $1-17$.

Meda, AL, Lamien, CE, Compaoré, MM, Meda, RNT, Kiendrebeogo, M, Zeba, B, Millogo, JF and Nacoulma, GO (2008) Polyphenol content and antioxidant activity of fourteen wild edible fruits from Burkina Faso. Molecules 13: 581-594.

Mueller, M, Hobiger, S and Jungbauer A (2010) Anti-inflammatory activity of extracts from fruits, herbs and spices. Food Chem. 122: 987-996.

Mukherjee, PK, Maitya, N, Nemaa, NK and Sarkar, BK (2011) Bioactive compounds from natural resources against skin aging. Phytomedicine 19: 64-73.

Murillo, E, Britton, GB and Durant, AA (2012) Antioxidant activity and polyphenol content in cultivated and wild edible fruits grown in Panama. J. Pharm. Bioallied Sci. 4: 313-317.

Nayak, J and Chand, BU (2015) Antioxidant potential of some lesser known wild edible fruits of Odisha. Euro. J. Exp. Bio. 5: 60-70.

Orhan, IE and Khan, MTH (2014) Flavonoid derivatives as potent tyrosinase inhibitors- $\mathrm{A}$ survey of recent findings between 2008-2013. Curr. Top. Med. Chem. 14: 1486-1493. 
Pandey, KB and Rizvi, SI (2009) Plant polyphenols as dietary antioxidants in human health and disease. Oxid. Med. Cell. Longev. 2: 270-278.

Rana, YS, Tiwari, OP, Krishan, R and Sharma, CM (2018) Determination of nutritional potential of five important wild edible fruits traditionally used in Western Himalaya. Int. J. Life Sci. 6 (1): 79-86.

Saini, R, Dangwal, K, Singh, H and Garg, V (2014) Antioxidant and antiproliferative activities of phenolics isolated from fruits of Himalayan yellow raspberry (Rubus ellipticus). J. Food Sci. Technol. 51: 33693375.

Saini, R, Garg, V and Dangwal, K (2012) Comparative study of three wild edible fruits of Uttarakhand for antioxidant, antiproliferative activities and polyphenolic composition, Int. J. Pharma Biosci. 3: 158167.

Saini, R, Garg, V and Dangwal, K (2013) Effect of extraction solvents on polyphenolic composition and antioxidant, antiproliferative activities of Himalyan bayberry (Myrica esculenta). Food Sci. Biotechnol. 22: 887894.

Rice-Evans, CA (2002) Trease and Evans Pharmacognosy, 15th ed. Saunders, China.

Gorinstein, S, Poovarodom, S, Kruszewska, H, Leontowicz, M, Namieśnik, J,Vearasilp, S, Haruenkit, R, Ruamsuke, P, Katrich, E and Tashma Z (2011) Antioxidant properties and bioactive constituents of some rare exotic Thai fruits and comparison with conventional fruits: In vitro and in vivo studies. Food Res. Int. 44: 2222-2232.

Seal, T (2011) Antioxidant activity of some wild edible fruits of Meghalaya state in India. Adv. Biol. Res. 5: 155-160.

Seal, T, Chaudhuri, K and Pillai, B (2013) Effect of solvent extraction system on the antioxidant activity of some selected wild edible fruits of Meghalaya state in India. J. Chem. Pharm. Res. 5: 276-282.

Singh, H, Lily, MK and Dangwal, K (2015) Evaluation and comparison of polyphenols and bioactivities of wild edible fruits of North-West Himalaya, India. Asian Pac. J. Trop. Dis. 5: 888-893.

Singh, H, Lily, MK and Dangwal, K (2017) Viburnum mullaha D.DON fruit (Indian Cranberry): A Potential Source of Polyphenol with rich antioxidant, anti-elastase, anticollagenase and anti-tyrosinase activities. Int. J. Food Prop. 20: 1729-1739.

Singleton, VL, Orthofer, $\mathrm{R}$ and LamuelaRaventos, RM (1999) Analysis of total phenols and other oxidation substrates and antioxidants by means of Folin-Ciocalteu reagent. Method Enzymol. 299: 152-178.

Siqueira, EMDA, Rosa, FR, Fustinoni, AM, Via, L, Sant'Ana, PD and Arruda, SF (2013) Brazilian Savanna fruits contain higher bioactive compounds content and higher antioxidant activity relative to the conventional red delicious apple. PLOS One 8: $1-7$.

Sun, J, Chu, YF, Wu, X and Liu, RH (2002) Antioxidant and antiproliferative activities of common fruits. J. Agr. Food Chem. 50: 7449 7454.

Wang, H, Cao, GH and Prior, RL (1996) Total antioxidant capacity of fruits. J. Agr. Food Chem. 44: 701-705.

Zhang, QY, Li, R, Zeng, GF, Liu, B, Liu, H, Shu, Y, Liu, ZK, Qiu, ZD, Wang, DZ, Miao, HL, Li, M Y and Zhu, RZ (2014) Dihydromyricetin inhibits migration and invasion of hepatoma cells through regulation of MMP-9 expression. World $J$. Gastroenterol. 20: 10082-10093.

$* * * * * * * * *$ 